\title{
Factorial Experimental Design Optimization of Solid Phase Microextraction (SPME) Conditions for Analysis of Butylated Hydroxytoluene (BHT) in Bottled Water
}

\author{
Norma B. Tombesi ${ }^{a}$, Rubén H. Freije ${ }^{a}$ and Fabio Augusto ${ }^{*, b}$ \\ ${ }^{a}$ Química Ambiental, Universidad Nacional del Sur, Avda. Alem 1253, B8000CPB Bahía Blanca - Argentina \\ ${ }^{b}$ Instituto de Química, Universidade Estadual de Campinas, CP 6154, 13084-971 Campinas - SP, Brazil
}

\begin{abstract}
BHT é um antioxidante usado como aditivo em alguns alimentos e em plásticos de embalagens, e sua presença em água mineral engarrafada é possível devido à migração do aditivo contido nas paredes do recipiente. Planejamento fatorial foi empregado para determinar os valores ótimos para os parâmetros operacionais principais na análise de hidroxitolueno butilado (BHT) em água engarrafada usando microextração em fase sólida (SPME) direta e em headspace na etapa de pré-concentração. Os parâmetros otimizados foram $\mathrm{pH}$, temperatura e força iônica da amostra. A separação, deteç̧ão e quantificação dos extratos foi efetuada por cromatografia gasosa acoplada a espectrometria de massas. Experimentos preliminares foram realizados para selecionar a melhor fibra para o procedimento de extração. Fibras de polidimethilsiloxano (PDMS) foram selecionadas, e a metodologia otimizada aplicada com sucesso na extração e quantificação de BHT em amostras reais de água mineral e mineralizada engarrafada.
\end{abstract}

BHT is an antioxidant utilized as additive in some foods and in packaging plastics, and its presence in bottled mineral water is possible due to its migration from bottle walls to the contents. A factorial experimental design was utilized to obtain the optimum values for the main operational parameters in the analysis of butylated hydroxytoluene (BHT) in bottled water using headspace and direct solid-phase microextraction (SPME) in the pre-concentration step. The parameters optimized were sample $\mathrm{pH}$, temperature and ionic strength. The separation, detection and quantitation of the extracts were performed by gas chromatography coupled to mass spectrometry. Preliminary experiments were made to select the best fiber for the extraction procedure. Polydimethylsiloxane (PDMS) fibers were selected, and the optimized methodology was successfully applied to the extraction and quantitation of BHT in real samples of mineral and mineralized bottled water.

Keywords: SPME, GC-MS, factorial experimental design, BHT, bottled water

\section{Introduction}

Solid Phase Microextraction, introduced by Arthur and Pawliszyn in $1990{ }^{1}$ as a modern alternative to traditional sample preparation technology, is able to address many of the requirements put forward for analytical research. ${ }^{2}$ Several advantages can be pointed out in relation to this technique, such as it is solvent free, fast, uses the whole sample for analysis, requires only small amounts of sample and the fibers are highly reusable. It has been successfully applied for the analysis of diverse organic compounds from different matrixes. ${ }^{3}$

Application of SPME to determinate phenolic compounds has already been reported. ${ }^{4}$ The European

* e-mail: augusto@iqm.unicamp.br
Union (EU) has classified several phenols as priority contaminants and the 80/778/EC directive states a maximum concentration of $0.5 \mu \mathrm{g} \mathrm{L}^{-1}$ for total phenols in drinking water (individual concentrations should be under $\left.0.1 \mu \mathrm{g} \mathrm{L}^{-1}\right) .{ }^{5}$ Since 1947, 2,6-di-tert-butyl-4-methylphenol or 3,5-di-tert-butyl-4-hydroxytoluene (BHT) is an antioxidant widely used especially as an additive in some industrialized foods and packaging plastics ${ }^{6}$ and it may thus migrate into the packages contents. ${ }^{7}$ Controversial effects of BHT ingestion on public health were considered. ${ }^{8}$ A preliminary report on the specific application of direct immersion SPME for BHT determination (using a PDMScoated fibers) in plastic-bottled water was already done, ${ }^{9}$ suggesting that this technique is a good alternative for fast and accurate analyse; however, further optimization optimization was found to be necessary before proposing it as a routine procedure. 
SPME method optimization can be achieved in a traditional univariate trial, studying each factor separately, or by a chemometric approach based on the use of an optimum set of experiments (experimental design) which allows the simultaneous variation of all experimental factors studied, and the distinguishing of interactions among them that are not detectable with the classical experimental methods. ${ }^{10}$

This paper deals with the optimization of the analysis of BHT in water samples using such an experimental design. After preliminary, univariate studies evaluating the capabilities of different fibers, the effects of temperature, $\mathrm{pH}$ and salinity were evaluated by a two-level factorial design to obtain the optimal conditions for direct immersion (D-SPME) and headspace (HS-SPME) modes. Finally the performance of the optimized method was demonstrated analyzing real samples of mineral and mineralized bottled water.

\section{Experimental}

\section{Equipments}

All chromatographic separations were performed using a HP-6890 GC coupled to a HP-5972 Mass Selective Detector (Hewlett-Packard Corp., Avondale - PA) fitted with a HP-5 capillary column ( $30 \mathrm{~m} \times 0.25 \mathrm{~mm} \times 0.25 \mu \mathrm{m})$. Helium at 1 $\mathrm{mL} \min ^{-1}\left(36 \mathrm{~cm} \mathrm{~s}^{-1}\right)$ was used as a carrier gas. The following column oven temperature program was adopted: $80^{\circ} \mathrm{C}$ to $210{ }^{\circ} \mathrm{C}$ at $20^{\circ} \mathrm{C} \mathrm{min}^{-1}$ and then hold for $1 \mathrm{~min}$. All injections were performed manually. In all cases, the SPME fiber was kept for $5 \mathrm{~min}$ in the injection port at $250^{\circ} \mathrm{C}$ operated in splitless mode; under these conditions, no peaks were observed in blank runs performed between injections. The MS was operated with an electron energy of $70 \mathrm{eV}$. For the preliminary experiments and for the SPME method optimization, runs were performed in the TIC mode (scanned mass range form $\mathrm{m} / \mathrm{z}=35 \mathrm{D}$ to $500 \mathrm{D}$ ); for quantitative experiments SIM mode was adopted, monitoring the fragment with $m / z=205 \mathrm{D}$ (peak with a relative abundance of $100 \%$ in the BHT spectrum). Peaks were identified by comparison with the mass spectra library of Hewlett-Packard (NBS75K) and with retention data time of known standards.

\section{Chemicals and solutions}

BHT ( $>99 \%$ purity) was purchased from MerckSchuchardt, Germany. A primary stock solution $\left(20.00 \mathrm{~g} \mathrm{~L}^{-1}\right)$ of BHT was prepared by dissolving $0.5000 \mathrm{~g}$ of this analyte in $25.00 \mathrm{~mL}$ of pesticide-grade acetone (U.V.E., Buenos Aires, Argentina); the working $40 \mathrm{mg} \mathrm{L}^{-1}$ stock solution was prepared diluting the primary stock in acetone. Both stock solutions were stored at $4{ }^{\circ} \mathrm{C}$ in the refrigerator. Aqueous test samples (renewed each day) were prepared by dilution of suitable amounts of the working stock solution in deionized water. Other chemicals included analytical grade $\mathrm{NaCl}$ (Anedra, Buenos Aires, Argentina) and a Titrisol 0.1 mol L-1 $\mathrm{HCl}$ solution (Merck, Darmstadt, Germany).

\section{SPME preliminary univariated experiments}

To select the best fiber for the remaining experiments, fibers coated with $100 \mu \mathrm{m}$ polydimethylsiloxane (PDMS), $85 \mu \mathrm{m}$ polyacrylate (PA) and $65 \mu \mathrm{m}$ polydimethylsiloxane divinylbenzene (PDMS-DVB) housed in manual SPME holders (Supelco, Bellefonte - PA), were tested. The fibers were conditioned prior to use according to the supplier's instructions. Direct extractions from a $19.8 \mu \mathrm{g} \mathrm{L}^{-1}$ aqueous test solutions at $\mathrm{pH} 6.5$ and room temperature, without addition of $\mathrm{NaCl}$ and with extraction times ranging from $15 \mathrm{~min}$ to 60 min, were tested with the three fibers. Unless stated to the contrary, all measurements were done in triplicate.

\section{Multivariated optimization of extraction conditions}

The optimization of the main operational parameters of the SPME procedure (sample $\mathrm{pH}$, temperature and ionic strength) was carried out both for direct (D-SPME) and headspace (HS-SPME) modes, using a $40 \mu \mathrm{g} \mathrm{L}^{-1}$ aqueous solution of BHT as test sample. Direct SPME was performed by placing $15 \mathrm{~mL}$ sample aliquots in amber vials (maximum capacity) capped with PTFE-coated septa; HSSPME was performed by placing $10 \mathrm{~mL}$ aliquots in similar vials. The extraction time was $15 \mathrm{~min}$. A multivariate simultaneous approach was initially adopted to study the effects of variations of the chosen parameters on extraction efficiency, using a set of experiments arranged through a $2^{3}$ factorial design. ${ }^{11}$ The values for the upper $(+)$ and lower (-) levels of each variable were: $\mathrm{pH} 2.5$ and 6.5; temperature $=25^{\circ} \mathrm{C}$ and $75^{\circ} \mathrm{C}$; and ionic strength $=$ zero and $30 \mathrm{~g} \mathrm{NaCl} / 100 \mathrm{~mL}$ solution. Special statistical treatment was performed using the trial version of the software Design-Expert 6.0.7 (Stat-Ease Inc., Minneapolis - MN). To complement this multivariate assessment, univariate studies of ionic strength (using aqueous samples containing zero to $30 \% \mathrm{NaCl} \mathrm{w} / \mathrm{v}$ ) and extraction times (from $5 \mathrm{~min}$ to $60 \mathrm{~min}$ ) were also performed.

\section{Quantitative evaluation}

To determine the linearity and limits of detection of the optimized method, an analytical curve was determined 
using aqueous solutions of BHT with concentractions ranging from $0.04 \mu \mathrm{g} \mathrm{L}^{-1}$ to $40.0 \mu \mathrm{g} \mathrm{L}^{-1}$. For each point triplicate extractions were carried out. Then real samples of commercial and mineralized bottled water were analyzed using external standard calibration.

\section{Results and Discussion}

\section{Fiber screening}

Figure 1 shows the extraction profiles (peak area $\times$ extraction time) for the fibers evaluated. It is clear that, for all fibers, the equilibration time is greater than $60 \mathrm{~min}$. For this extraction time, the fiber extraction efficiency order is $\mathrm{PA}<\mathrm{PDMS} / \mathrm{DVB}<\mathrm{PDMS}$. To determine the statistical significance of the differences observed between the fibers, the data was submitted to an ANOVA test complemented by the post hoc contrast test of Scheffé, ${ }^{12}$ whose results are shown on Table 1. The results of the ANOVA test shows that, with $95 \%$ probability and except for short extractions $\left(\mathrm{t}_{\mathrm{ext}}=15 \mathrm{~min}\right)$, the results obtained with the tested fibers can be considered statistically different $\left(\mathrm{F}>\mathrm{F}_{\text {crit }}\right)$. A more detailed insight can be provided by the Scheffé test: the efficiency of PA fiber is different from that of the other

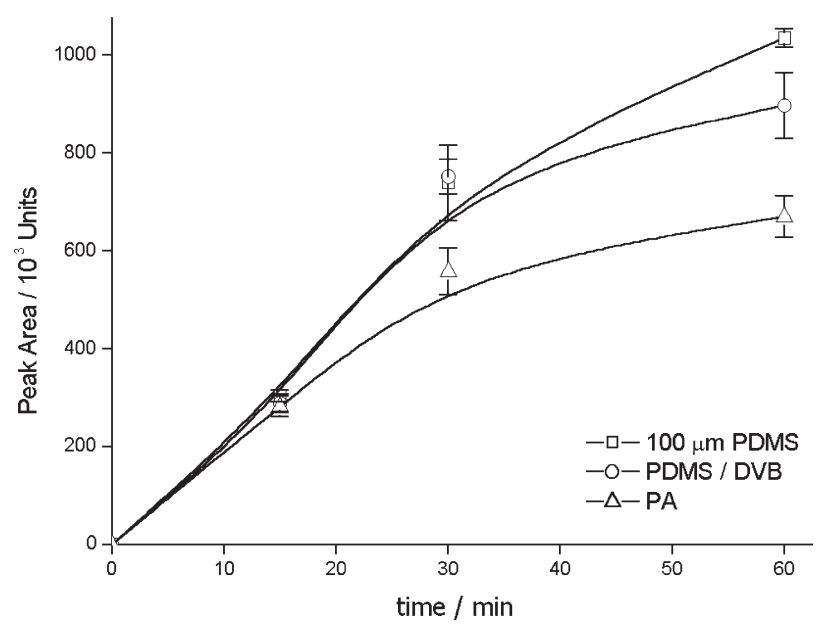

Figure 1. BHT extraction profiles for $100 \mu \mathrm{m}$ PDMS, PDMS / DVB and PA fibers. Direct extractions from $19.8 \mu \mathrm{g} \mathrm{L}^{-1}$ neutral aqueous solutions of BHT.

Table 1. Results of ANOVA test (F-values and associated probabilities, P) between the PDMS, PDMS / DVB and PA peak areas for 15 min, $30 \mathrm{~min}$ and $60 \mathrm{~min}$ extraction, and corresponding Scheffé contrast significance tests

\begin{tabular}{cccl}
\hline $\mathrm{t} / \mathrm{min}$ & $\mathrm{F}^{\text {a }}$ & $\mathrm{P} \%$ & Scheffé test \\
\hline 15 & 1.21 & 36.3 & all fibers are equivalent \\
30 & 10.9 & 1.00 & PA ${ }^{1}$ PDMS and PA ${ }^{1} \mathrm{DVB}$ \\
60 & 46.3 & 0.02 & no equivalence between fibers \\
\hline
\end{tabular}

${ }^{a} \mathrm{~F}_{\text {crit }}(2,6)=5.14(95 \%$ confidence level $)$. fibers for extraction times greater than $15 \mathrm{~min}$; for $60 \mathrm{~min}$ extractions, all efficiencies are different. Considering the higher extraction efficiency provided, $100 \mu \mathrm{m}$ PDMS was selected for the remaining experiments.

\section{Multivariated optimization of the SPME method}

Figures 2 and 3 shows the peak areas found for BHT after direct and headspace extractions using PDMS 100 $\mathrm{mm}$ fiber and different operational conditions. The effects of the studied variables on the extraction efficiency and the corresponding interactions between the variables calculated after the $2^{3}$ factorial planning experiments, as well as the ANOVA analysis of these effects, to assess their statistical significance, are shown in Table 2.

Both for direct and headspace SPME, the most important operational variables are the temperature and ionic strength of the sample. According to Table 2, the temperature accounts for $22.1 \%$ (D-SPME) and $32.6 \%$ (HS-

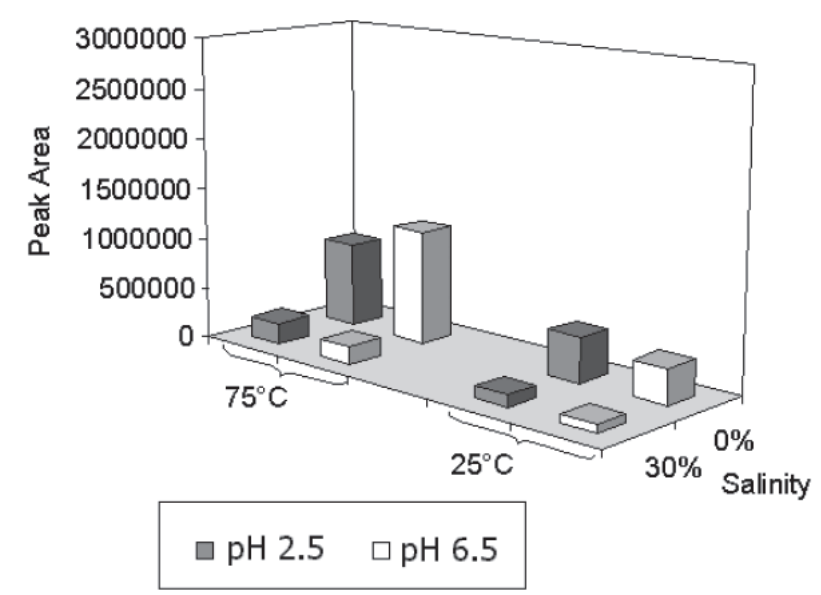

Figure 2. Peak areas for D-SPME of $40 \mu \mathrm{g} \mathrm{L}^{-1}$ aqueous solutions of BHT obtained under varied operational conditions.

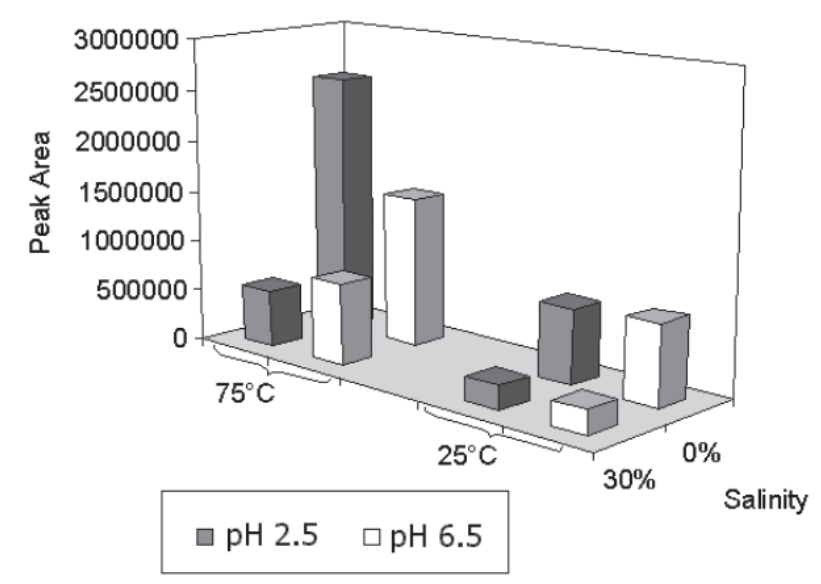

Figure 3. Peak areas for HS-SPME of $40 \mu \mathrm{g} \mathrm{L}^{-1}$ aqueous solutions of BHT obtained under varied operational conditions. 
Table 2. Effects and interactions from the $2^{3}$ factorial design experiments for direct (D-) and headspace (HS-) SPME of BHT, their relative percent contribution to the total variance (Contr.\%), and significance from ANOVA test F-values and associated probabilities, $\mathrm{P}$

\begin{tabular}{ccccrr}
\hline & & \multicolumn{2}{c}{ Factorial } & Design & \multicolumn{2}{c}{ ANOVA } \\
& Variable & Effect $/ 10^{3}$ & Contr. $\%$ & \multicolumn{1}{c}{$\mathrm{F}$} & \multicolumn{1}{c}{$\mathrm{P} \%$} \\
\hline \multirow{5}{*}{ D-SPME } & $\mathrm{T}$ & 338 & 22.1 & 84.6 & $<0.01$ \\
& $\mathrm{i}$ & -541 & 56.8 & 217.18 & $<0.01$ \\
& $\mathrm{pH}$ & 30 & 0.18 & 0.68 & 42.3 \\
& $\mathrm{~T} \times \mathrm{i}$ & -248 & 12.0 & 45.70 & $<0.01$ \\
& $\mathrm{~T} \times \mathrm{pH}$ & 97 & 1.82 & 6.96 & 1.8 \\
& $\mathrm{i} \times \mathrm{pH}$ & -73 & 1.05 & 4.00 & 6.3 \\
& $\mathrm{~T} \times \mathrm{i} \times \mathrm{pH}$ & -98 & 1.89 & 7.22 & 1.6 \\
\hline & $\mathrm{T}$ & 896 & 32.6 & 190.96 & $<0.01$ \\
& $\mathrm{i}$ & -988 & 44.4 & 227.13 & $<0.01$ \\
& $\mathrm{pH}$ & -193 & 1.66 & 10.36 & 0.67 \\
& $\mathrm{~T} \times \mathrm{i}$ & -454 & 8.96 & 42.81 & $<0.01$ \\
& $\mathrm{~T} \times \mathrm{pH}$ & -204 & 1.54 & 13.40 & 0.29 \\
$\mathrm{i} \times \mathrm{pH}$ & 330 & 4.85 & 26.67 & 0.02 \\
& $\mathrm{~T} \times \mathrm{i} \times \mathrm{pH}$ & 332 & 4.92 & 30.23 & 0.01 \\
\hline
\end{tabular}

T: temperature; i: ionic strength.

SPME) of the total observed variance; as for ionic strength, the contribution of this parameter is, respectively, $56.8 \%$ (D-SPME) and 44.4\% (HS-SPME). Both for D- and HSSPME, the temperature effect is positive and the ionic strength effect is negative (i.e., increasing the temperature and decreasing the ionic strength of the media would result in better extraction efficiency). Regarding the temperature effect, for direct extraction its impact on the extraction equilibrium depends on the variation of the enthalpy associated to the partition of the analyte between the fiber coating and the sample: the observed reduction of the extracted amounts of BHT with higher extraction temperatures shows that this process is endothermic, ${ }^{13}$ which is not usual in SPME. As for HS-SPME, the temperature/efficiency dependence is more complex ${ }^{14}$ and, therefore, such a direct interpretation of the observed temperature effect is not possible.

The effect of ionic strength on BHT extraction also is not that customarily found in direct SPME (normally, addition of $\mathrm{NaCl}$ to the sample improves the extraction efficiency both for direct and headspace operation). However, phenols such as BHT contain a hydroxyl group in their structures, which can increase their affinity for the solutions containing electrolytes and result in the observed comportment, which has already been reported for the extraction of related chemical species. ${ }^{15}$ Anyway, considering that in the multivariate experiments only two levels of this variable were tested, a further confirmation of this odd observation was performed with headspace extractions of samples with $\mathrm{NaCl}$ concentrations ranging from $3.75 \%$ to $30 \%$, using $\mathrm{T}=75^{\circ} \mathrm{C}$ and $\mathrm{pH}=2.5$. The results of this additional study are shown in Figure 4. It can be clearly seen that there is a sharp, roughly linear decrease on the extraction efficiency with the concentration of $\mathrm{NaCl}$ (a $1.0 \%$ increment on the concentration of $\mathrm{NaCl}$ causes a reduction of $\sim 2.7 \%$ in the BHT peak area), which confirms the results from the factorial design.

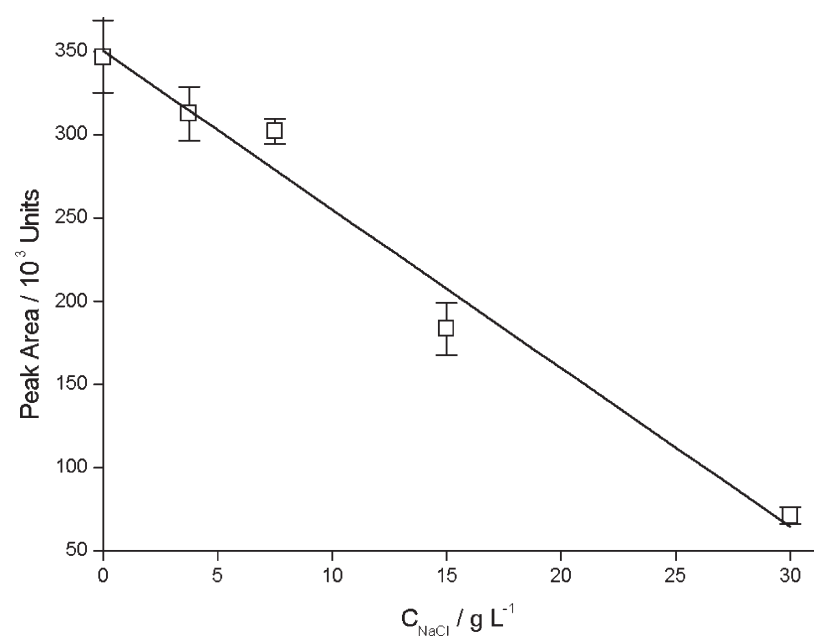

Figure 4. Dependence between BHT peak areas and concentraction of $\mathrm{NaCl}$ on the sample after HS-SPME.

Regarding the effect of $\mathrm{pH}$ and adopting $95 \%$ as the confidence level, its impact is not statistically significant for D-SPME. For HS-SPME its effect is significant, although its contribution to the total variance $(1.66 \%)$ is much less pronounced than that of the other variables. Phenols - such as BHT - are weak acids and control of the $\mathrm{pH}$ of the sample is in general considered mandatory in procedures involving these species, potentially having a pronounced impact on method sensitivity. ${ }^{16}$ However, since BHT is expected to be a weaker acid than other phenols due to the bulky alkyl groups present in its molecule, ${ }^{17}$ the effect of $\mathrm{pH}$ on its extraction is expected to be marginal, specially for the low $\mathrm{pH}$ values adopted of this study (2.5 and 6.5), an this agrees with the data obtained. Finally, the negative $\mathrm{pH}$ effect on HS-SPME is in agreement with general SPME theory: lowering the sample $\mathrm{pH}$ shifts the BHT dissociation equilibrium towards the formation of the neutral extractable species, improving the extraction efficiency.

Another aspect of Table 2 worthy if discussing is the interaction between the variables (e.g., $\mathbf{T} \times \mathbf{i}$ ): for both extraction modes, all interactions (except $\mathbf{i} \times \mathbf{p H}$ for DSPME) are statistically significant. The implication of this observation is that conventional univariate methods can not be used to optimize the operational conditions studied here. Therefore, experiments planned according to multivariate procedures, such as the factorial design employed here, should be used since the impact of these variables upon the extraction efficiency is interdependent. 
Several simultaneous physico-chemical processes occurs during the extraction: transport of the analyte through the bulk matrix to the fiber/sample or fiber/headspace interface, its diffusion through the headspace, the static layer surrounding the fiber and the PDMS fiber coating, acid dissociation, etc. ${ }^{14}$ It is reasonable to suppose that the combined effects of the studied media-conditioning variables on the kinetics and thermodynamics of the involved unitary process result in a complex overall effect, not predictable or able to be determined by a simple univariated study. It is also noted that, for HS-SPME (which, compared to D-SPME, involves additional mass transfer steps), the impact of the measured inter-variable interactions is even more expressive, as indicated by the corresponding $\mathbf{F}$ parameters and the associated probabilities: even at a $99.5 \%$ confidence level these figures are statistically significant.

The optimum values for the parameters studied on the factorial planning experiments discussed above are $\mathrm{T}=75^{\circ} \mathrm{C}$, no $\mathrm{NaCl}$ addition and pH 2.5 (HS-SPME) or 6.5 (D-SPME). Under the optimized conditions the extraction efficiency of HS-SPME is remarkably superior to that of D-SPME. Therefore, this extraction mode was selected for the remaining experiments. The determination of the equilibrium time for HS-SPME under the optimized conditions was performed after extractions of solutions containing $40 \mu \mathrm{g} \mathrm{L}^{-1}$ BHT for times ranging from $5 \mathrm{~min}$ to $30 \mathrm{~min}$. The extraction profile obtained is shown in Figure 5. It can be seen that equilibrium is reached after $c a .15 \mathrm{~min}$ of extraction, which was therefore applied for the remaining experiments.

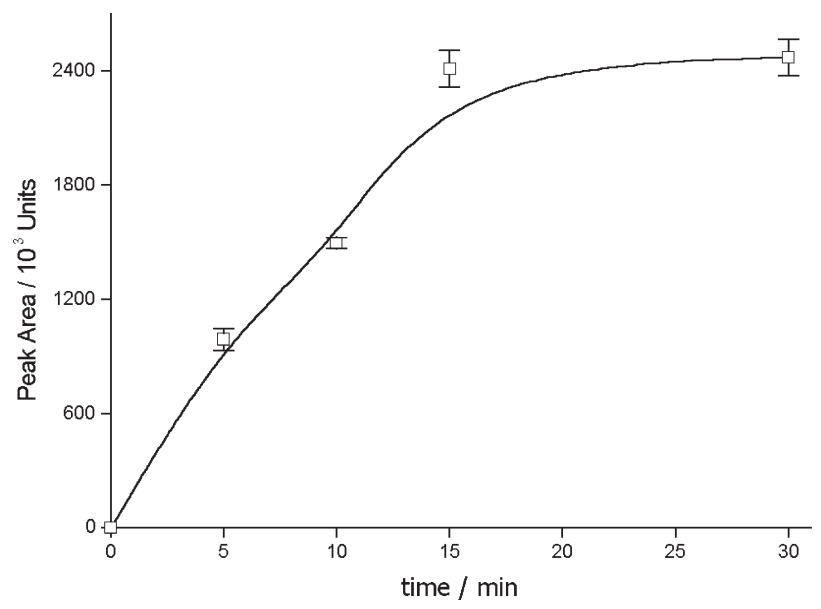

Figure 5. HS-SPME extraction profile for BHT using the optimized procedure.

Quantitative evaluation and application of the HS-SPME method

The quantitative figures of merit of the optimized HSSPME method (linearity, sensitivity and precision) were assessed through the analytical curve shown in Figure 6. The precision is acceptable: the correlation coefficient of the curve is 0.9999 and the relative standard deviation of the data ranges from $1.3 \%$ to $10.1 \%$. Although there is no visible deviation of linearity in the plot, an additional ANOVA test was performed to check for lack of fit in the linear regression. ${ }^{18-21}$ Since the estimated $\mathbf{F}$ value of 0.0777 ( $\mathbf{P}=98,8 \%)$ is lower than the $\mathbf{F}_{\text {crit }}$ for $95 \%$ confidence level $\left(\mathbf{F}_{\text {crit }}=3.71\right)$, the null hypothesis (the straight line model describes the relationship between signal and BHT concentration) cannot be rejected. The limits of detection and quantitation (defined respectively as three and ten times the ratio between the standard deviation of the intercept and the slope) were $0.43 \mu \mathrm{g} \mathrm{L}^{-1}$ and $1.45 \mu \mathrm{g} \mathrm{L}^{-1}$.

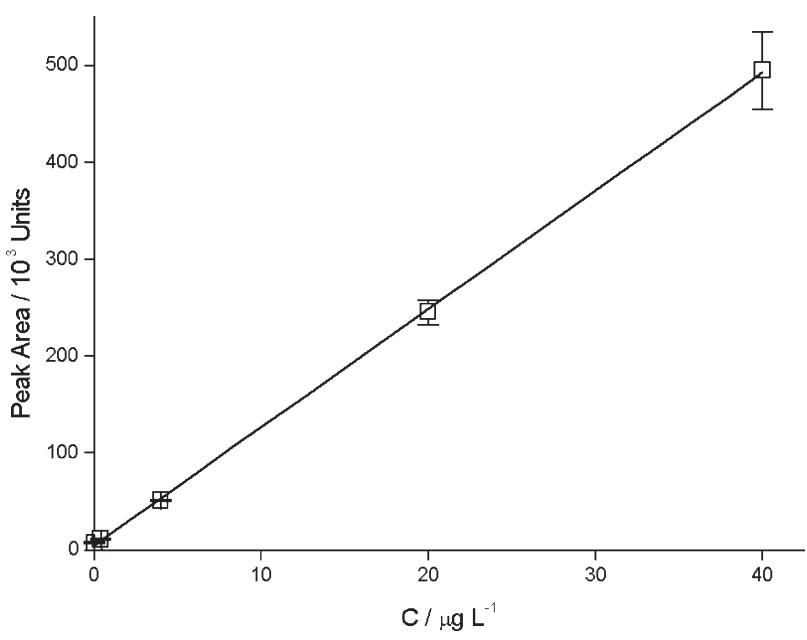

Figure 6. External standardization HS-SPME analytical curve for $0.04 \mu \mathrm{g} \mathrm{L}^{-1}$ to $40 \mu \mathrm{g} \mathrm{L}^{-1}$ BHT. Curve equation: $\mathrm{C}=(12.20 \pm 0.09) \mathrm{A}$ $+(4.6 \pm 1.8) ; \mathrm{C}=\mu \mathrm{g} \mathrm{L}^{-1} \mathrm{BHT}$ and $\mathrm{A}=10^{3}$ area units.

To demonstrate the performance of the optimized SPME method, nine mineral and mineralized bottled water samples were analyzed for the presence of BHT. The results are shown in Table 3. The contaminant was found only in three out of the nine samples studied; in the samples where BHT was detected, its concentration was on the $\mu \mathrm{g} \mathrm{L}^{-1}$ level.

Table 3. Concentrations of BHT $\left(\mu \mathrm{g} \mathrm{L}^{-1}\right)$ found in samples of commercial mineral and mineralized bottled water (average of triplicate measurements)

\begin{tabular}{ccc}
\hline Sample & $\mathrm{V} / \mathrm{L}^{\mathrm{a}}$ & $\mathrm{C}$ \\
\hline $\mathrm{A}$ & 0.5 & $2.3 \pm 0.4$ \\
$\mathrm{~A}$ & 1.5 & $2.1 \pm 0.2$ \\
$\mathrm{~B}$ & 0.5 & n.d. \\
$\mathrm{C}$ & 0.5 & n.d. \\
$\mathrm{D}$ & 1.5 & n.d. \\
$\mathrm{E}$ & 0.5 & $1.5 \pm 0.1$ \\
F & 1.5 & n.d. \\
G & 2.0 & n.d. \\
H & 0.35 & n.d. \\
\hline
\end{tabular}

${ }^{\mathrm{a}}$ Volume of the bottle; ${ }^{\mathrm{b}}$ n.d. $=$ not detected. 


\section{Conclusions}

A two-level factorial experimental design enables obtaining optimal conditions for Solid Phase Microextraction of BHT in water with a reasonable number of experiments and taking into account the interaction between the variables affecting the SPME process. Extraction times were reduced to half and the limits of detection and quantification lowered an order of magnitude, compared to previous preliminary work. ${ }^{9}$ This optimized methodology was successfully applied to the extraction of BHT in real samples of mineral and mineralized bottled water. BHT was detected in one out of three of the samples, and the measured concentrations were above the recommended levels according to the European Union standards for total phenols in drinking water. ${ }^{5}$

\section{Acknowledgements}

The authors thank Dr. Carol Hollingworth Collins for reviewing this manuscript.

\section{References}

1. Arthur, C.L.; Pawliszyn, J.; Anal.Chem. 1990, 62, 2145.

2. Lord, H.; Pawlyszyn J. ; J. Chromatog. A 2000, 885, 153.

3. http://www.science.uwaterloo.ca/chemistry/pawliszyn/, accessed in August, 2003

4. Buchholz, K.D.; Pawliszyn, J.; Environ. Sci. Technol. 1993, 27, 2844.

5. Llompart, M.; Lourido, M.; Landín, P.; García-Jares, C.; Cela, R.; J. Chromatog. A 2002, 963, 137.

6. IARC Monographs on the Evaluation of Carcinogenic Risks to Humans and their Supplements; International Agency for Research on Cancer (IARC), IARC Press: Lyon, 1986, 40, 161.
7. Schwope, A.D.; Till, D.E.; Ehntholt, D.J.; Sidman, K.R.; Whelan, R.H.; Schwartz, P.S.; Reid, R.C.; Food Chem. Toxicol. 1987, 25, 317.

8. Fries, E.; Puttmann, W.; Water Res. 2002, 36, 2319.

9. Tombesi, N.B.; Freije, R.H.; J. Chromatog. A 2002, 963, 179.

10. Castro Mejías, R.; Natera Marín, R.; García Moreno, V.; García Barroso, C.; J. Chromatog. A 2002, 953, 7.

11. Barros Neto, B.; Scarminio, I.S.; Bruns, R.E.; Planejamento e Otimização de Experimentos, Unicamp: Campinas, 1995.

12. Scheffé, H.; The Analysis of Variance, John Wiley: New York, 1959.

13. Arthur, C.L.; Killam, L.M.; Buchholz, K.D.; Pawliszyn, J.; Anal. Chem. 1992, 64, 1960.

14. Pawliszyn, J.; Solid Phase Microextraction, Wiley-VCH: New York, 1997.

15. Buchholz, K.D.; Pawliszyn, J.; Anal. Chem. 1994, 66, 160.

16. Buchholz, K.D.; Pawliszyn, J.; Environ. Sci. Technol. 1993, 27, 2844.

17. Bizarro, M.M.; Cabral, B.J.C.; Santos, R.M.B.; Simões, J.A.M.; Pure Appl. Chem. 1999, 71, 1249.

18. Analytical Methods Committee (AMC); Is my Calibration Linear?, The Royal Society of Chemistry: London, 2000.

19. Massart, D.L.; Vandelginste, B.G.M.; Buydens, L.M.C.; Jong, S.; Lewi, P.J.; Smeyers-Verbeke, J.; Handbook of Chemometrics and Qualimetrics: Part A, Elsevier: Amsterdam, 1997.

20. EURACHEM; The Fitness for Purpose of Analytical Methods - a Laboratory Guide to Method Validation and Related Topics, LGC: Teddington, 1988.

Received: September 10, 2003

Published on the web: August 17, 2004

FAPESP helped in meeting the publication costs of this article. 